\title{
Research on the Challenge and Countermeasure of MOOC in College English Teaching
}

\author{
Yili Xue \\ Xi’an International University, Shaanxi, Xi’an, 710077
}

Keywords: MOOC; English Teaching; Challenge

\begin{abstract}
After the implementation of the new curriculum reform, the domestic education industry has undergone tremendous changes and the people's attention to education has reached an unprecedented height. In the new environment of the new curriculum reform, how to reform the teaching mode, how to classify the classroom teaching from the traditional model, and the improvement of the English level has become the problem that many English teachers need to think about. Traditional English teaching model in the new teaching environment also need to make new breakthroughs, the teaching model also needs to be more close to the contemporary university teaching development status quo. The emergence of MOOC is a new teaching model of innovation, is the new learning method of innovation. It can enable students to get more education resources, to achieve the sharing of educational resources, but also to enable students to break the practice and geographical limitations. However, MOOC in the study for the convenience of English, but also to the English teaching has brought new challenges. How to correctly understand the MOOC, how to grasp the opportunities and challenges brought about by how to solve the plight of the situation is that we need to think carefully. According to the relevant information, combined with their own experience, the challenges brought about by the MOOC discussion, and give a preliminary solution.
\end{abstract}

\section{Introduction}

In 2008, Mu concept began to shape, six years ago, began to sweep the world. With the emergence of MOOC, this new, to break the traditional teaching mode of teaching methods because of its many advantages quickly become the new trend of education. It's free, high quality, and has a wealth of educational resources, while no geographical restrictions, no time limit, a time for many scholars flocked to. In this case, the current college English teachers to bring a lot of thinking, this new model and the new method of course to bring convenience to students, but on the other hand teachers should also see the challenges they bring, MOOC of double-sided, in order to bring their own teaching a new breakthrough and inspiration

\section{The Meaning of MOOC}

MOOC is the abbreviation of Massive Open Online Course, which means "large-scale online open course", is based on curriculum and teaching theory and the development of mobile intelligence technology to support the formation of emerging forms of online courses [1]. MOOC in its form not only has a large-scale features, which depends on the spread of its extensive range, as well as the large number of participants, MOOC learning participants all over the world, not geographical restrictions. Secondly, openness, this feature is mainly because the MOOC itself is free of charge to the learner, the accepted learners are from all corners of the globe, while MOOC in the course of its content contains some educational information, and learning methods , The student's learning environment and related educational resources are shared, open [2]. Model is innovative, MOOC is different from our traditional network teaching, although the current network teaching there are many, but most still do not change medicine, still cannot get rid of the traditional model of the shackles, in the teaching is still spoon the old one. But the MOOC will be completely broken this model, he will be divided into different sections of the course content, each section is 
only about ten minutes, and in this refined content will set some questions to guide the study consciously think, and only through in order to carry out the next stage of learning, which greatly improve the student's participation and learning efficiency, so that students in the MOOC learning can be a good constraint on their own, positive thinking, greatly increased the students of autonomy [3].

\section{The Challenges of MOOC in College English Teaching}

The Impact on Teaching Mode. MOOC and the traditional English teaching model is different, it is more intuitive feeling. Traditional teaching materials and teacher lectures have greater limitations, but the production of English teaching video, whether from the auditory, visual or other senses, have a more intense impact, can make people quickly into the state, and Put themselves in place for transposition thinking, with more powerful than the traditional model of appeal and persuasion. The construction of MOOC, whether in the teaching mode of innovation, or in the open space, are more than the traditional English teaching model has a huge change, this change can greatly attract the attention of students, MOOC for the interest the orientation is very great, only to fully stimulate the enthusiasm of students to learn interest in order to give full play to the students' subjective initiative, the passive to take the initiative, more with less. Only when the students are interested, they will focus on learning, only the classroom vivid, in order to allow students to experience the joy of learning. English teaching knowledge points, wide coverage, practical and strong, teachers in a limited time to a large number of knowledge points to be transmitted, it is easy to cause classroom boring, so that students get weariness. And especially in the moment, students for paper teaching visual fatigue make traditional English teaching more difficult. The construction of MOOC, through more humane, close to the way students to knowledge point of view, to reduce the difficulty of teaching, improve the coverage of knowledge, make up for the limitations of traditional teaching, improve student interest.

Challenges for Teaching Content. As mentioned earlier, a major feature of MOOC is openness and broadness, not only in its participation in the number and spread, but also in its educational content. Mu taught in the teaching content is very extensive, in English teaching, because its instructors and learners are from different countries of different regions, so in teaching more local culture into. In English teaching, both in terms of vocabulary, learning visually than traditional teaching has a great advantage. In addition, the teaching video of MOOC is more abundant and comprehensive in the same period of time than the traditional written course, and it is more general and more comprehensive. In general, this type of lecture video is more Short, so the transmission of knowledge points are after repeated refining the results, so more professional and refined, so that students learn more easily grasp. This model breaks the traditional teaching of stereotyped boring, for the classroom to give a new color, which requires teachers to continue to innovate in the teaching model, from the constraints of the traditional model of liberation, with a new look at English teaching to innovate new models. This makes the traditional teaching must be the current teaching content to make changes in order to more in line with the current student development, to make teaching content richer and more three-dimensional.

Challenges for Students. MOOC has a traditional classroom cannot match the characteristics of free and no geographical restrictions, therefore, MOOC since the beginning of the application, the registration volume is huge, but its lower participation rate and pass rate, but also makes MOOC encounter multi-criticism. But it is difficult for students to self-restraint, participation rate is getting lower and lower, and the participation of the course will directly affect the learner's learning effect, and eventually lead to low pass rate. So an important question arises, learning opportunities do not represent the effectiveness of learning, how students correct their motives, cultivate the ability to arrange their own learning plans and build a knowledge system, which is a challenge for learners [4]. 


\section{Challenges of the Combination of MOOC in College English Teaching}

Start from the Students, So Students Have a Correct Understanding of Learning. Compared with the traditional classroom teaching, the free MOOC has the characteristics of flexible learning time and optional learning location. It is suitable for the contemporary college students, but the students' self-restraint ability is poor in this environment. Therefore, students should first establish a correct values, recognizing that MOOC for improving the overall quality of individuals, the accumulation of knowledge and future career development has an important role in order to stimulate the enthusiasm of learning, and actively participate in curriculum activities, the accumulation of online learning experience; Second, learners need to have independent learning ability, both pre-school self-orientation, self-exploration and self-examination, self-reflection after learning, but also independent arrangements for learning plans and self-building knowledge system [5].

Change the Traditional Teaching Model and Make Teaching Model Innovation. At present, in English teaching, teaching methods of traditional single, or follow the traditional way of scripting, boring, poor flexibility. But the English majors for the quality of the classroom requirements are very high, in the listening exercises and the English scene to restore, etc., so that the English teaching model innovation is particularly important, teachers can guide students to learn classes, let the positive thinking, training students' divergent thinking and English thinking. Traditional teaching materials and teachers have great limitations, whether it is from the listening angle, visual or other senses, or in the mode of teaching are more boring, and the new model of innovation, so that teachers are positive and correct to guide students to MOOC and English classroom combination of learning, will allow students to more three-dimensional to observe, to think, you can let students quickly into the state, but also to the English professional this special professional can be closer to reality, with more than the traditional model strong appeal and persuasion, so that students can greatly improve the efficiency of learning.

Improve the Overall Quality of Teachers. The level of teachers 'teaching and the quality of English directly determine the level of English learning of students, but also determines the effect of students' English thinking. In response to the challenge from the MOOC, the teacher's teaching ability is the key, how to enhance the teachers for the classroom control, how to correctly apply to the MOOC, how to choose a good teaching and educational resources for students to better study , Teachers must be required to have a high professionalism and high professional ability to play a leading role for students, to be more professional teaching, for students to better solve the problem, the correct pace of the classroom grasp. Therefore, the first study of English learning from the teacher's own, to improve the overall level of teachers to ensure the quality of teaching and teaching efficiency. So that teachers with a full of enthusiasm, rich knowledge and scientific teaching methods to carry out a high level of English teaching, so that students cannot only efficient learning, but also under the leadership of teachers in the cultivation of English thinking.

\section{Conclusion}

With the participation of MOOC, more and more learners have accepted this new learning mode. In the development of MOOC, there are many influences on college English and many challenges to English teaching. In the current university classroom, more and more educators recognize the importance of changing the educational philosophy and the transformation of the educational methods, and realize the importance of the innovation of English teaching methods. English teaching as an important part of the university curriculum, how to improve the quality of the classroom, change the traditional teaching mode, teaching methods of innovation has become the majority of mathematics teachers need to think about the problem, in the MOOC trend, how to correctly respond from MOOC challenge, how to better build English class, improve the current level of teaching worthy of English teachers thought. 


\section{References}

[1] Zhao Xiaodan. Muju (MOOC) on the impact of college English classroom teaching and challenges [J]. Science and Education (late), 2016, 05: 149-150.

[2] Liu Shan Ji. College English audio-visual lectures trial MOOC + flip classroom teaching mode of the way [J]. Jiamusi Vocational College Journal, 2016, 10: 318-319.

[3] Li Lin. From a questionnaire to see the new situation under the college English teachers in oral teaching challenges and countermeasures[J]. Bilingual learning, 2007, 09: 12-13.

[4] Bai Yingcai.Study on the reform of college English teaching in art colleges under the background of transitional period[J]. Liaoning Provincial Higher Education Institute. Liaoning Provincial Higher Education Society 2014 Annual Conference Outstanding Paper Third Prize Summary [J Liaoning Provincial Higher Education Society: 2014: 5.

[5] Wang Dezhi, Yuan Qiao. Talking about the teaching of college English audio-visual in the environment of "MOOC" (MOOCs)[J]. Journal of Huanggang Normal University, 2014,05: 153-155. 